\title{
INEQUALITY AND THE EROSION OF TRUST AMONG THE POOR: EXPERIMENTAL EVIDENCE
}

\begin{abstract}
This paper uses a subtle experimental treatment to examine how perceptions of income inequality affect generalized trust and the willingness to cooperate with others. It hypothesizes that inequality reduces prosocial attitudes mostly among low-income citizens, who are very sensitive to changes in their relative status. The results of the survey experiment suggest that perceiving the income distribution as more unequal has particularly detrimental effects on the pro-social attitudes of the poor, with potential implications for their ability to mobilize politically. The erosion of trust among the poor due to increases in income inequality may be an important mechanism hindering mobilization in favor of redistribution.
\end{abstract}

Keywords: Trust, inequality, social capital

JEL classifications: Cultural Economics • Economic Sociology, Political Economy, Personal Income, Wealth, and Their Distributions 


\section{Introduction}

Income inequality is often considered detrimental because it undermines many basic pillars of democracy such as political interest (Solt, 2008), voter turnout (Beramendi and Anderson, 2008; Galbraith and Hale, 2008; Solt, 2008) and the quality of political representation (Bartels, 2008). Of particular concern is the claim that income inequality reduces generalized trust, an important pro-social attitude that lowers transaction costs and helps solve social dilemmas such as collective action problems (Uslaner, 2008; Rothstein and Uslaner, 2005; Uslaner, 2002; Zak and Knack, 2001). A reduction of trust can trigger a cascade of negative outcomes, serving as an important mechanism linking inequality to lower democratic quality.

To date, evidence supporting or disputing the claim that income inequality undermines trust derives mostly from observational data, which makes it difficult to demonstrate causal effects. The results are highly sensitive to decisions about model specification. The number of countries available to study is small, and they differ in many respects. Within countries, inequality changes only slowly over time, which limits longitudinal variation. The challenges to causal inference are so serious that some scholars believe that when studying the effects of income inequality on political outcomes "cause and effect relations are impossible to specify exactly" (Delhey and Newton, 2005, p. 311).

While income inequality is difficult to manipulate, perceptions of income inequality can be changed. This provides a way to assess the effects of perceptions on preferences. Understanding this link is of utmost importance because the political impact of inequality is mediated by how people appraise this phenomenon. As Dahl states: "Between a condition of objective inequality and the response of a disadvantaged person, lie the perceptions, evaluations, expectations - in short, the psyche — of the individual." (1971, p. 95). This paper contributes to knowledge about the relationship between perceptions of income inequality and pro-social attitudes by reporting the results of a survey experiment that subtly manipulates the distribution of income. The survey experiment, which was administered to a representative sample of the Dutch population in March 2012, manipulated the response categories of an income question to create the perception that the Netherlands had either an egalitarian or a non-egalitarian income distribution. A control group was not administered any income question. This experimental design can be applied to study the effect of perceptions of income inequality on other relevant attitudes and behaviors. 
The results show that perceptions of income inequality can erode pro-social attitudes and that this reduction may be heterogeneous across income groups. In the experiment, higher levels of perceived income inequality reduce interpersonal trust and norms of cooperation mainly among low-income respondents. The results are consistent with the view that those more harmed by increases in inequality exhibit more detrimental effects, possibly with important political consequences. Workhorse models in political economy suggest that inequality is self-correcting if it motivates the poor to engage in political action in support of redistribution. The finding that the erosion of pro-social attitudes caused by inequality is concentrated among the poor adds one additional reason why the self-correcting mechanism may not work. Trust and other pro-social attitudes facilitate participation in elections, engagement with the political system and political organization. If the pro-social attitudes of the poor are most negatively affected by rising inequality this may lead to a vicious circle in which inequality worsens even further as the poor refrain to participate, are more alienated from the political system, and less able to organize.

\section{Trust and inequality: Mechanisms and heterogeneous effects}

Many studies have documented a negative correlation between income inequality and generalized trust (Delhey and Newton, 2005; Freitag and Bühlmann, 2009; Hooghe et al., 2009; Ichida et al., 2009; Uslaner, 2002; Zak and Knack, 2001; Bjørnskov, 2007) ${ }^{1}$. One theoretically and empirically important question that has received little attention in previous research is who is more affected by changes in income inequality. The argument can cut in different ways, depending on the main mechanism through which inequality reduces trust. Because this research concentrates on the effects of perceptions of income inequality, the most relevant mechanisms for our purposes are psychological. According to Uslaner and Brown $(2005,870)$, there are two main mechanisms that link inequality to trust, both of which are psychological: "First, high levels of inequality lead to less optimism for the future. Greater pessimism means less trust. Second, where there is a lot of inequality, people in different economic strata will be less likely to have a sense of shared fate. They will be less likely to trust one another."

The first mechanism runs through pessimism about the future (Uslaner 2002, Uslaner and Brown 2005). This pathway can lead us to expect that inequality has heterogeneous effects on high- and lowincome citizens because it affects their prospects very differently. When income inequality is low, all citizens can hope to have a good life by that society's standards. It makes sense to be optimistic and trust. In very unequal societies, by contrast, the life opportunities of people at the upper and the bottom ranks differ widely. High status individuals can still maintain a general positive outlook on life. However, low 
status individuals find it hard to progress and will be more likely to see the current system as unfair (Uslaner 2002).

The claim that inequality leads mostly poor people to believe that the distribution of income is unfair fits well with theories of inequity aversion (Fehr and Schmidt 1999). It is well documented that people loss more utility from an increase in inequality when it is to their disadvantage than when it is to their advantage and that disadvantageous inequality is judged as more unfair. If poor people believe that the distribution of income is unfair in unequal contexts, this will lead them to distrust the system that produces that distribution with possible negative consequences for trust in general.

In addition, the idea that inequality reduces socio-psychological well-being particularly among low status individuals is consistent with extensive epidemiological research which finds that low status individuals are more adversely affected by inequality even at the molecular level (Wilkinson et al. 2009). Low-income individuals --and low-status animals more generally-- exhibit lower self-esteem and more stress and anxiety than high-income individuals, and this difference in psychological well-being is more pronounced in unequal societies. For these different reasons, it is reasonable to expect that perceiving a more unequal distribution will have predominantly detrimental effects on the poor and will erode trust more among low-status individuals than among high-status individuals.

The second mechanism posed by Uslaner is that inequality erodes the sense of being members of a community with a shared fate. Altruism or trust extend more intensively to others who people consider similar to themselves and income inequality undermines pro-social attitudes because it increases the social distance between individuals (Alesina and La Ferrara, 2002, p. 288; Banerjee et al., 2007). The argument extends to any characteristic that increases social distance between members such as ethnic heterogeneity (Alesina and La Ferrara 2001). This view is consistent with classical studies in social psychology (e.g. Kramer and Brewer 1984) showing that membership in homogeneous groups is more conducive to fostering a strong sense of group identity -going from "I" to "we" - than membership in heterogeneous groups and that members of a group are more likely to trust each other than to trust nonmembers. Importantly, in this view income inequality should reduce trust homogeneously for high and low income citizens because increased social distance reduces in-group identification for everyone. The same reasoning applies to perceptions: perceiving a more unequal income distribution should lead to increased social distance from others and reduce trust for all. 
While scant, previous empirical evidence mostly supports the idea that income inequality is particularly harmful for the attitudes and behavior of low-status citizens. Using cross-national survey data, Solt (2008) finds that income inequality had particularly negative effects on the levels of political interest, political discussion, and voter turnout among individuals at the lower end of the income distribution. Cardenas (2003) reports the results of a public goods game simulating a decision-making process about the uses of a forest among rural villagers in Colombia. When the distribution of actual wealth among the players was more unequal they cooperated less and made less efficient decisions and this negative effect was driven by the poorer players, who cooperated less when the distance between their wealth and the wealth of other players increased.

This paper examines whether modifying the perceptions of income inequality affects trust and whether the effects are heterogeneous for people at different ends of the income distribution. While the theoretical predictions are ambiguous, I expect that low-income respondents may be particularly sensitive to an experimental treatment that modifies perceptions of income inequality.

\section{Approaches to the study of the consequences of income inequality}

Previous empirical research about the effect of inequality on trust draws on observational data with mixed results upon closer inspection. While the studies reported above find a negative effect, some studies have found that the correlation is not significant (Herreros and Criado, 2008; Leigh, 2006) or that it is not significant when controlling for racial and ethnic fragmentation (Alesina and La Ferrara, 2002, pp. 2212). Still others have found mixed results when using different indicators of inequality (Gustavsson and Jordahl, 2008). Longitudinal trends in the US support the hypothesis that inequality reduces trust, but Britain is a counter-example, where we observe increasing levels of both inequality and trust over time (Nannestad, 2008).

These empirical studies draw almost exclusively on observational data, which presents three main challenges. First, the results are highly sensitive to model specification. Income inequality is correlated with a wide range of observable and unobservable variables, such as ethnic heterogeneity, political institutions, or religious traditions, making it unrealistic to assume that regression models are correctly specified. The second problem is reverse causality if "high trust could theoretically induce a feeling of solidarity across income segments that would create support for redistributive policies"(Bjørnskov, 2007, p. 6). A third problem derives from decisions about the selection of countries. For instance, Scandinavian 
countries, which show high levels of both trust and income equality, may exert a disproportionate influence on the results in small samples. One approach to dealing with these identification problems and to estimate the effects of income inequality is to use instrumental variables (IV). Uslaner ( 2008) has used a variety of instrumental variables ranging from ethnic fractionalization to risk of terrorism or the electoral system, and Bjørnskov (2007) uses GDP per capita and political orientation as instruments of inequality. However, the validity of the instruments is often questionable.

Natural experiments in which some economic or political shock modifies the income distribution are an ideal research design, but large income shocks such as those generated with the discovery of oil have multiple consequences besides their impact on inequality.

Because of these difficulties, researchers have used laboratory experiments to study the causal effects of income inequality, but the results are mixed. Smith (2011) creates unequal distributions of income in a standard trust game ${ }^{2}$ by assigning half the subjects a low endowment ( 5 dollars) and the other half a high endowment (15 dollars). The players were matched in four types of pairings according to their income: low-low, low-high, high-low, and high-high. Surprisingly, senders with a low endowment paired with subjects with a high endowment were more likely to trust than subjects in other pairs. In another experiment, Anderson et al. (2006) find that income inequality induced in the laboratory did not affect behavior in trust games. By contrast, Anderson, Mellor and Milyo (2008) manipulated the level and distribution of a payment given to participants in a public goods game ${ }^{3}$ and found that inequality reduced contributions to the public good especially when respondents had information about the income of other players.

The external validity of laboratory experiments may be low because they do not mimic the process that assigns individuals to positions in the income distribution. The consequences of income inequality may differ depending on whether individuals perceive the income distribution as fair (acquired through effort) or unfair (exogenously assigned by luck or the researchers). The treatment may also be too short-lived to have an effect. The actual position in the income distribution is an enduring individual characteristic with long-lasting effects on life prospects, self-image, and beliefs. Perhaps high-income individuals suddenly placed at the bottom of the income distribution in a laboratory experiment do not react in ways that are typical for individuals who actually belong to the lower end of the distribution. Laboratory studies typically use student subjects that are not representative of the population, but if income inequality has heterogeneous effects across population subgroups, the experimental results may not apply to less educated or older populations. 
A rather different approach is to take people's positions in the income distribution as given, hence avoiding some of the problems referred above, and using an experimental design that modifies perceptions of the income distribution. Haisley, Mostafa and Lowenstein (2008) study the behavioral consequences of poverty (to be distinguished from inequality) by priming low-income participants to perceive their actual income as low or as high in a survey context. Unlike laboratory experiments, this strategy does not attempt to assign the actual income of participants exogenously. Rather, the experiment uses implicit comparisons with other income groups to modify the perception of income. The survey included a question on yearly income with two randomly assigned conditions: one defined income brackets in a way that primed respondents to believe that their income was average and the other primed them to think that they had a very low income. ${ }^{4}$ Using a similar design, Mo (2011) studied the effect of relative poverty on risk attitudes in rural Nepal. These two studies use a strong treatment. In both cases, the income brackets were defined in ways that depart dramatically from the actual income distribution (for example having "Less than 100,000 dollars" as the lowest income bracket). This paper builds on this approach but modifies it in two important ways: by focusing on perceived income inequality rather than perceived poverty and using a much more subtle treatment.

\section{Design and data collection}

To study the impact of income inequality on pro-social attitudes, I designed a survey experiment that was embedded in the Longitudinal Internet Studies for the Social sciences (LISS) panel, a high quality online survey administered to a random probability sample of Dutch citizens (Scherpenzeel, 2011). Since 2007, the LISS panel has collected monthly data from all members aged 16 or higher of the selected households ${ }^{5}$. LISS provides computers and Internet connection to the elected households that do not have them, thus ensuring that the panel includes non-Internet users. Respondents are paid to participate, and they receive multiple reminders for each wave. Response rates are generally high, ranging between 60 and 80 percent. A total of 1,693 persons answered the survey between March $3^{\text {rd }}$ and March $7^{\text {th }} 2012$, but the analyses are based on the 1,484 cases for whom we have responses of sufficient quality. ${ }^{6}$ I also use background variables asked in the same wave.

The experiment manipulated the categories of a five-category household income question with the aim of modifying the perceptions of income inequality. There were three treatment conditions: the low-inequality condition, the high-inequality condition, and the control group. Only subjects in the first 
two conditions were asked about their household's total net income, while subjects in the control condition were not asked this question.

The five categories of the income questions were designed to mirror income quintiles. The question wording claimed that "Households in the Netherlands can be categorized into 5 groups, depending on their total net income," suggesting that the income brackets corresponded to common types of households. Respondents were asked about their households' total net income, and the text clarified, "Total net income means the sum of all net incomes of all members of the household. Net income is the income after the deduction of taxes and social premiums."

Table 1 about here

The two lower income categories matched the actual two lower income quintiles as reported by the Dutch statistical service for 2009 (see Table 1). The first category was "up to 17,000 euros" and the second category was "between 17,000 and 24,000 euros." The purpose of the decision to keep the two lower income groups constant across the two treatments was not to force middle-income households to fall into the bottom categories. Modifying the lower income categories could be regarded as a manipulation intended to lift some people out of (perceived) poverty--understood here simply as belonging to the lowest income groups rather than more technically as falling below a relative poverty line--or make some fall into low-income groups. In order to avoid forcing some people in and out of the lowest income groups, I kept the two lower income brackets constant across the treatment conditions. This decision also matches the evolution of income at lower income groups, which has remained stable fairly stable in recent years.

The main aim of the treatment was to manipulate perceptions of the spread of the income distribution. Hence, the manipulation happened at the three upper income categories. The experiment intended to prime respondents to see themselves in two different income distributions: an egalitarian distribution, in which the rich have incomes that are not dramatically higher than the incomes of the poor, and an unequal distribution, in which the difference between the rich and the poor is steep. This design also attempts to capture features of recent changes in the income distribution. Income inequality can increase because the wealthy become wealthier, the poor become poorer, or both. Recent growth in income inequality has been primarily driven by disproportionate increases in the income of people at the upper end of the distribution (Atkinson et al., 2009), and the treatment attempts to mimic this development. 
In the low-inequality condition, the income distribution (as hinted by the income brackets) was compact. The fifth income category was defined as earning more than 32,000 euros a year. This category suggested that the poorer people of the highest income quintile earned roughly twice as much as the richer people of the first quintile. Survey research on desired inequality levels suggests that most people perceive differences of this magnitude as desirable (Norton and Ariely, 2011).

In the high-inequality condition, the distribution was more spread out. The fifth income category was for households that made " 82,000 euros or more." This category suggested that the poorest members of this category earn almost five times as much as the richer members of the first quintile. The design allowed respondents to answer "I would rather not say" and "I don't know." The implications of this decision for the results are discussed below. The exact wording of the experimental manipulations was as follows:

Figure 1 about here

The most important dependent variable in this study is generalized trust which was measured using the standard formulation: "Generally speaking, would you say that most people can be trusted, or that you can't be too careful in dealing with people?" The rating scale was shown horizontally ranging from 0 ("You can't be too careful") to 10 ("Most people can be trusted"). Respondents were also offered a "Don't know" option. This measure of generalized trust has been criticized because it is a self-report rather than a behavioral measure. A widely cited study found a low correlation between self-reported trust and trusting behavior in the first stage of an investment game (Glaeser et al., 2000), although self-reported trust did predict trustworthy behavior. More recently, scholars have marshaled abundant evidence which generally supports the validity of the generalized trust measure (see for example Bjørnskov, 2007, p. 2; Nannestad, 2008).

I also include a second question which measures reported willingness to cooperate with others. This variable, also used by Knack and Keefer (1997), is not the main focus of the analysis but serves as a test of the general expectation that income inequality undermines pro-social attitudes. The two main mechanisms should apply not only to trust but also to other pro-social attitudes if both pessimism and increased social distance undermine desirable inter-personal dispositions. The exact wording attempted to reduce concerns about social desirability as follows: "For some people, citizens should pursue first and foremost their self-interest even when it clashes with the interests of others. For other people, citizens 
should always cooperate with others even at a personal cost. And of course there are people with an opinion somewhere in between." The rating scale was shown horizontally ranging from 0 ("Citizens should pursue self-interest") to 10 ("Citizens should cooperate with others"). Again, respondents could also choose "I don't know."

The distribution of both variables was one-peaked and skewed towards pro-social attitudes, with considerable variation in the responses (see Figure 2). The mean generalized trust score was 5.7, with a standard deviation of 2.4. Only 20 persons answered, "I don't know." The mean of the dispositions towards cooperation question was 6.5 , with a standard deviation of 1.8. For that question, only four respondents answered "I don't know." While the distribution of the dependent variables is somewhat skewed, there is also enough variation in the positions to examine the effect of the treatment on the selfreported attitudes. The correlation between the two variables is moderate in size at 0.24.

Figure 2 about here

Respondents may have been more likely to misreport their income in order to move upwards in the income distribution in one treatment condition than in the other. In order to explore this possibility, Table 2 reports the percentage of respondents in the treatments conditions who chose each income bracket. The percentage of respondents in low-income households -defined as respondents who report that their household's net income is "up to 17,000 euros" or "between 17,000 and 24,000 euros"- was extremely similar across the two treatment conditions: About 36 percent $^{7}$ reported net household incomes of 24,000 euros or less. This suggests that the treatments did not affect the motivation to misreport income.

As could be expected, many respondents (38 percent) chose the highest income bracket in the low-inequality condition (32,000 euros or more), whereas in the high-inequality condition 41 percent chose the third income bracket (24,000 - 42,000 euros).

Table 2 about here

A second concern is that choosing the options "I would rather not say" and "I don't know" is correlated with income differently across treatment conditions. If that were the case, non-response would modify the composition of the sample in the experimental conditions, although the differences would need to be extremely large in order to change the composition within each income groups in a way that 
affects the results. I have explored this possibility by correlating net household income as reported in a separate module of the survey and non-response to the experimental question. In both conditions, there is a substantial correlation between low income and non-response to the income question. Importantly for this research, however, the correlation is similar in size in both conditions. ${ }^{8}$

\section{Results}

The treatments did not modify self-reported attitudes when focusing on the whole sample. The mean generalized trust score was 5.7 in the low-inequality condition, slightly lower, at 5.59, in the high inequality condition, and 5.74 in the control condition (which did not ask about income). For the second dependent variable, norms of cooperation, the mean was again somewhat higher in the low-inequality condition (6.47) than in the high-inequality condition (6.37). In the control condition, the mean was 6.54. None of the differences was statistically significant. The sole fact of priming people to think about money could in theory produce some difference in reported attitudes. Importantly, the lack of differences between the control group and the treatment conditions suggests that priming people to think about their income did not affect trust or norms of cooperation.

Do we observe treatment effects among respondents in a low socio-economic position? When focusing on low-income respondents, or other groups of low-status citizens, ${ }^{9}$ the results reveal that the high-inequality treatment reduced pro-social attitudes. This claim is robust to alternative operationalizations of socio-economic status.

The first relevant comparison is between respondents of lower and higher incomes as reported in the experimental income question. I divide respondents in two groups, the high- and the low-income group, collapsing the two lower and the three higher income categories in the treatment conditions. Collapsing the five categories in two groups is necessary for comparability. This is because in the low inequality condition, the fifth (the highest) income group is defined by earning 32,000 euros or more, whereas in the high inequality treatment it is defined by earning 82,000 euros or more. Hence, the composition of the highest income groups varies across conditions. If we found differences in attitudes, it would be impossible to tell if such differences are due to the different socio-economic composition of the groups or to treatment effects. In order to address this, I use as a cut-point the highest value that is fixed across treatment conditions, which is whether respondents belong to the first or second income groups (and hence earn less than 24,000 euros) or earn more than that. In the analyses, individuals were 
categorized as low-income if they reported net household incomes of 24,000 euros or less and as highincome if they reported higher incomes.

Table 3 displays the mean levels of generalized trust and norms of cooperation by treatment condition and type of respondent. Low-income respondents in the high-inequality condition had an average trust score of 5.04 in a 0 to 10 scale (std. err. $=0.20 ; \mathrm{N}=157$ ). In the low-inequality condition, the mean value was 5.43 (std. err. $=0.20 ; \mathrm{N}=143$ ). The 0.4 points difference is statistically significant at the 90 percent confidence level $(\mathrm{p}=0.08)$. By contrast, there was no statistically significant difference in the reported levels of trust among high-income people. This finding supports the claim that inequality is particularly detrimental for the pro-social attitudes of the most destitute members of society. The effect is in the expected direction among the most underprivileged respondents. The magnitude of the effect is moderate, but it is noteworthy to find an effect at all given the extreme subtlety of the treatment.

The effect of the high-inequality treatment on attitudes towards cooperation was statistically significant at conventional levels $(\mathrm{p}=0.007)$ among low-income respondents. The average score of support for cooperation was 6.66 in the low-inequality condition and 6.15 in the high-inequality condition. This difference of 0.5 points is also moderate, at $3 / 10$ of a standard deviation. By contrast, the treatment did not affect attitudes towards cooperation among high-income respondents. Again, this finding suggests that perceived income inequality has negative effects on the pro-social attitudes of people at the lower end of the income distribution.

Table 3 about here

The higher income categories in the experimental treatment are very heterogeneous. For instance, in the fifth income bracket includes individuals with household incomes of 32,000 euros or more in the low inequality condition and citizens with incomes of 82,000 euros or more in the high inequality condition. One important concern with the experimental results is that the null effect among the high income group is driven by respondents with very high incomes but that respondents with medium incomes also exhibit a reduction in trust, or vice versa.

The second comparison addresses this possibility using information collected in a different wave of the study, which asked questions about household income. I subset the individuals in the high income group in two subgroups: The middle income group ranges from 24.000 to 35.000 euros, which corresponds to percentiles 45 to 74 and the high income group is comprised by individuals in households 
that earn 35.000 euros or more, corresponding to percentiles 75 to 100. The sample size in the cells for the middle and high income groups range from 119 to 150. It is not possible to create more fine-grained categories because smaller cell sizes would make it impossible to find small or moderate treatment effects. Table 4 compares the responses in the high and low inequality treatments.

Table 4 about here

I find no significant differences in attitudes in the middle and the high income groups. For norms of cooperation, the effect of the treatment is clearly confined to low income respondents. For trust, the results suggest that there is a linear relationship such that the negative effect of the treatment on trust is reduced at middle levels of income and reversed at higher levels, but the experiment does not have sufficient statistical power to draw fine-grained conclusions.

The treatment effects may appear small in the previous analyses due to the fact that respondents were collapsed into overly broad income categories. Conversely, the differences across treatment conditions may not be significant when using alternative measures of income. To confirm the robustness of the results, I tested the interaction between various measures of social position and treatment status in a regression framework that allows examining the effects of the treatment at different income levels.

Table 5 reports the results of several regression models that test for the presence of an interaction effect + . The dependent variables are generalized trust in models 1 to 3 and norms of cooperation in models 4 to 6 . All models include treatment status as a predictor. The low-inequality condition is the reference category, and the high-inequality condition and the control condition are introduced as dummy variables. In model 1, socio-economic status is measured as net household income in units of 1,000 euros. ${ }^{10}$ Model 2 uses net personal income in units of 1,000 euros instead of household income. ${ }^{11}$ Model 3 uses education instead of income as a proxy for socio-economic position. Models 4 through 6 have norms of cooperation as the dependent variable, with the same right-hand side specification as Models 1 to 3 .

Table 5 about here

First, relative to the low-inequality condition, poor respondents in the high-inequality condition reported lower levels of generalized trust and a lower willingness to cooperate with others. All coefficients are, as expected, negative. The coefficients of the high-inequality dummy are quite large in 
magnitude, (ranging from -0.6 to -0.8 for trust and from -0.46 to -0.83 for willingness to cooperate, both variables range from 0 to 10 ). This suggests that for citizens with very low socio-economic resources the treatment caused a relatively large drop in their reported willingness to trust and cooperate.

Second, the analyses confirm that the effects of the treatment were heterogeneous across treatment conditions. All interaction terms of socio-economic position and treatment status had positive coefficients, suggesting that the negative effect of the high inequality treatment on pro-social attitudes is attenuated among high-income respondents.

The regression results suggest that the effects of the high-inequality treatment were larger for low-status respondents than for high-status respondents. I proceed to evaluate the substantive magnitude of the effects at different income levels. Figure 3 displays the marginal effects of the high-inequality treatment compared to the low-inequality condition on each dependent variable at different income levels. The graphs also present the confidence intervals at the 95 percent level. The marginal effects are derived from models 1 and $4 .{ }^{12}$ The scores are calculated for respondents in households with total net incomes ranging from 0 to 5,000 euros. Households with net monthly incomes of 1,000 euros are approximately at the $5^{\text {th }}$ percentile of the household income distribution, and households with 5,000 euros are approximately at the $95^{\text {th }}$ percentile (the median is 2,650 and the mean is 2,850 euros). Hence, the simulation covers the relevant range of the income variable.

Figure 3 about here

The estimations of marginal effects reveal that, relative to the low-inequality condition, the highinequality treatment had a negative and statistically significant effect on self-reported pro-social attitudes among respondents in low-income households (i.e. those who live in households with total monthly net incomes roughly below 2,000 euros). This conclusion holds for both generalized trust and willingness to cooperate. By contrast, for all higher income groups, the estimated marginal effects are not statistically significant, suggesting that the high-inequality treatment did not modify the responses of high-income respondents.

In summary, the findings of the multivariate analysis, using an alternative operationalization of income, confirm that the negative effect of a highly unequal perceived income distribution on pro-social attitudes was only found among respondents with a low socio-economic status. Respondents with a high 
income or education level were less sensitive to the treatment. They did not become less trusting or less willing to cooperate with others when the perceived distribution of income was more unequal.

\section{Discussion}

This study has used an original survey experiment to assess the claim that perceptions of income inequality undermine pro-social attitudes. Although it is not possible to manipulate actual income inequality in a survey context, the experiment subtly manipulated perceptions of the shape of the income distribution. The results suggest that changes in perceived income inequality reduce pro-social attitudes, but only among the socially disadvantaged.

This study finds experimental support for a relationship that until now had mostly been tested using observational data. Generalized trust is important because this attitude is thought to help solve social dilemmas (Rothstein and Eek, 2009), in which cooperation is beneficial to all participants but is only rational if almost all other agents also cooperate. The ability to solve social dilemmas makes it more likely that groups engage in mutually beneficial exchanges and in collective action. Internally valid evidence that income inequality reduces pro-social attitudes suggests that highly unequal societies are less able to overcome social dilemmas successfully. This finding is very timely as the distribution of income has become more unequal in advanced industrial democracies in recent decades (Brandolini and Smeeding, 2008; McCall and Percheski, 2010; Neckerman and Torche, 2007). This evolution is likely to accelerate due to skill-biased technological change and we may expect pro-social attitudes to erode further as income inequality increases, thus reducing societies' capacity to overcome social dilemmas.

The finding that the detrimental effects of income inequality on pro-social attitudes may be concentrated among the poor is particularly relevant. A decline in pro-social attitudes can impose additional obstacles to the political organization and mobilization of the poor, with consequences for their prospects of obtaining favorable social policies and proper representation. For instance, low trust and prosocial attitudes may particularly erode the propensity of low-income people to vote, join political parties or trade unions, and otherwise engage in the political process in unequal societies. Such differential demobilization of the poor would provide fewer incentives for political elites to defend their interests in the political process. The result can be a vicious circle in which inequality undermines the capacity of the poor to mobilize which in turn further exacerbates inequality. The results of a survey experiment need to be taken cautiously, but the finding that perceptions of income inequality may erode pro-social attitudes mostly among the poor is important and deserves further attention. 
Of course, this study has significant limitations. The treatment does not manipulate actual income inequality but only perceptions of inequality. The finding that an extremely subtle manipulation can affect reported attitudes is remarkable and suggests that humans are acutely aware of and sensitive to differences in relative status. A second limitation is that the dependent variables are self-reports rather than attitudinal measures. While usual in survey contexts, self-reports are more susceptible to social desirability biases. Further research is needed to validate the conclusions using behavioral measures. Third, the current design does not allow adjudicating between different possible mechanisms why perceptions of income inequality may affect pro-social attitudes. In particular, it cannot demonstrate that the treatment increases psychological distress only among low-status individuals or that it increases social distance and for whom. Fourth, the experiment only modifies one aspect of the income distribution, the spread of income as higher income brackets become wealthier. Other features of the income distribution that modify the shape in alternative ways may lead to different results (Lupu and Pontusson 2011).

While acknowledging these limitations, the study helps demonstrate that there is indeed a relationship between perceived levels of income inequality and pro-social attitudes. Hence, it complements and fills an important gap in a literature that, as reviewed above, has suffered from severe identification problems. This experimental strategy does not substitute other approaches, but is a needed complement to previous efforts. Importantly, the basic design presented here can be modified and extended in fruitful ways to address the limitations of this study and to analyze other questions. For instance, instead of creating a more unequal distribution by only altering the higher income categories, researchers can present respondents with income questions suggesting that the distribution has different shapes to test if the shape of inequality rather than the absolute amount is politically consequential. In order to study psychological mechanisms, such as levels of stress or emotions, these mediating outcomes can be measured just after the treatment. Furthermore, this experimental design can be applied to study the effects of perceptions of income inequality on other relevant outcomes that have received less attention than generalized trust to date.

\section{References}

Alesina, A., and LaFerrara, E. (2001) 'Trust in heterogeneous communities', Quarterly Journal of Economics, 115, 847-904.

Alesina, A. and La Ferrara, E. (2002) 'Who Trusts Others?', Journal of Public Economics, 85, 207-234. 
Anderson, L. R., Mellor, J. M. and Milyo, J. (2006) ‘Induced Heterogeneity in Trust Experiments', Experimental Economics, 9, 223-235.

Anderson, L. R., Mellor, J. M. and Milyo, J. (2008) 'Inequality and Public Good Provision: An Experimental Analysis', Journal of Socio-Economics, 37, 1010-1028.

Banerjee, A., Iyer, L. and Somanathan, R. (2007) 'Public Action for Public Goods', Handbook of Development Economics, 4, 3117-3154.

Bartels, L. M. (2008) Unequal Democracy: The Political Economy of the New Gilded Age, Princeton University Press.

Beramendi, P. and Anderson, C. (2008) Democracy, Inequality, and Representation: A Comparative Perspective, Russell Sage Foundation Publications.

Bjørnskov, C. (2007) 'Determinants of Generalized Trust: A Cross-Country Comparison', Public Choice, 130, 1-21.

Brandolini, A. and Smeeding, T. M. (2008) 'Inequality Patterns in Western Democracies: Cross-Country Differences and Changes over Time', American Journal of Political Science, 43, 649-80.

Cardenas, J. C. (2003) 'Real Wealth and Experimental Cooperation: Experiments in the Field Lab', Journal of Development Economics, 70, 263-289.

Dahl, R. (1971) Polyarchy: Participation and Opposition. New Haven: Yale University Press.

Delhey, J. and Newton, K. (2005) 'Predicting Cross-National Levels of Social Trust: Global Pattern or Nordic Exceptionalism?’, European Sociological Review, 21, 311-327.

Fehr, E. and Schmidt, K. M. (1999) 'A theory of fairness, competition, and cooperation', Quarterly Journal of Economics, 3, 817-868.

Festinger, L. (1954) 'A theory of social comparison processes', Human Relations, 7, 117-140.

Freitag, M. and Bühlmann, M. (2009) 'Crafting Trust', Comparative Political Studies, 42, 1537-1566.

Galbraith, J. K. and Hale, J. T. (2008) 'State Income Inequality and Presidential Election Turnout and Outcomes’, Social Science Quarterly, 89, 887-901.

Glaeser, E. L., Laibson, D. I., Scheinkman, J. A. and Soutter, C. L. (2000) 'Measuring Trust', The Quarterly Journal of Economics, 115, 811-846.

Gustavsson, M. and Jordahl, H. (2008) 'Inequality and Trust in Sweden: Some Inequalities Are More Harmful than Others', Journal of Public Economics, 92, 348-365.

Haisley, E., Mostafa, R. and Loewenstein, G. (2008) 'Subjective Relative Income and Lottery Ticket Purchases', Journal of Behavioral Decision Making, 21, 283-295.

Herreros, F. and Criado, H. (2008) 'The State and the Development of Social Trust', International Political Science Review, 29, 53-71. 
Hooghe, M., Reeskens, T., Stolle, D. and Trappers, A. (2009) 'Ethnic Diversity and Generalized Trust in Europe A Cross-National Multilevel Study’, Comparative Political Studies, 42, 198-223.

Ichida, Y., Kondo, K., Hirai, H., Hanibuchi, T., Yoshikawa, G. and Murata, C. (2009) 'Social Capital, Income Inequality and Self-Rated Health in Chita Peninsula, Japan: A Multilevel Analysis of Older People in 25 Communities', Social Science \& Medicine, 69, 489-499.

Knack, S. and Keefer, P. (1997) 'Does Social Capital Have an Economic Payoff? A Cross-Country Investigation', The Quarterly Journal of Economics, 112, 1251-1288.

Kramer, R. and Brewer, M. (1984) 'Effects of group identity on resource use in a simulated commons dilemma', Journal of Personality and Social Psychology, 46, 1044-1057.

Leigh, A. (2006) ‘Trust, Inequality and Ethnic Heterogeneity', Economic Record, 82, 268-280.

Lupu, N. and Pontusson, J. (2011) 'The Structure of Inequality and the Politics of Redistribution', American Political Science Review, 105, 316-336.

McCall, L. and Percheski, C. (2010) 'Income Inequality: New Trends and Research Directions', Annual Review of Sociology, 36, 329-347.

Mo, C. H. (2011) 'Perceived Relative Poverty and Risk: An Aspiration-Based Model of Vulnerability', Working paper.

Nannestad, P. (2008) 'What Have We Learned about Generalized Trust, If Anything?', Annual Review of Political Science, 11, 413-436.

Neckerman, K. M. and Torche, F. (2007) 'Inequality: Causes and Consequences', Annual Review of Sociology, 33, 335-357.

Norton, M. I. and Ariely, D. (2011) 'Building a Better America-One Wealth Quintile at a Time', Perspectives on Psychological Science, 6, 9.

Rothstein, B. and Eek, D. (2009) 'Political Corruption and Social Trust an Experimental Approach', Rationality and Society, 21, 81-112.

Rothstein, B. and Uslaner, E. M. (2005) 'All for All: Equality, Corruption, and Social Trust', World Politics, 58, 41-72.

Scherpenzeel, A. (2011) 'Data Collection in a Probability-Based Internet Panel: How the LISS Panel Was Built and How It Can Be Used', Bulletin of Sociological Methodology/Bulletin de Méthodologie Sociologique, 109, 56-61.

Smith, A. (2011) 'Income Inequality in the Trust Game', Economics Letters, 1, 54-56.

Solt, F. (2008) 'Economic Inequality and Democratic Political Engagement', American Journal of Political Science, 52, 48-60.

Solt, F. (2011) 'Diversionary Nationalism: Economic Inequality and the Formation of National Pride', The Journal of Politics, 73, 821-830.

Uslaner, E. M. (2002) The Moral Foundations of Trust, Cambridge University Press. 
Uslaner, E. M. (2008) Corruption, Inequality, and the Rule of Law: The Bulging Pocket Makes the Easy Life, Cambridge University Press.

Uslaner, E. M. and Brown, M. M. (2005) “Inequality, Trust, and Civic Engagement," American Politics Research, 31, 868-894.

Wilkinson, R. G et al. (2009) The Spirit Level: Why More Equal Societies Almost Always Do Better, London: Allen Lane.

Zak, P. J. and Knack, S. (2001) 'Trust and Growth', The Economic Journal, 111, 295-321.

\footnotetext{
${ }^{1}$ These studies use aggregate measures of income inequality together with individual-level survey data in order to measure trust.

${ }^{2}$ In a trust game, one player can send a number of points to a second player. Then the experimenter multiplies this points by a quantity (usually by three) and the second player can choose to send any fraction of the endowment back or keep it all for him or herself.

${ }^{3}$ Each session consisted of 30 decision-making periods with 8 participants. There were three conditions. In the egalitarian condition, the 8 subjects received 7.5 points. In the skewed condition, one subject received 20 points, 4 received 7 and 3 got 4 . In the symmetric condition, 3 received 10, 2 received 7.5 and 3 received 5.

${ }^{4}$ In the average income condition, respondents had to choose among five income brackets: Less than $\$ 10,000$; Between $\$ 10,001$ and $\$ 20,000$; Between $\$ 20,001$ and $\$ 40,000$; Between $\$ 40,001$ and $\$ 60,000$; More than $\$ 60,000$. In the relative poverty condition, the brackets were: Less than $\$ 100,000$; Between $\$ 100,001$ and $\$ 250,000$; Between $\$ 250,001$ and \$500,000; Between $\$ 500,001$ and \$1 million; More than $\$ 1$ million. The manipulation of the income brackets attempted to generate the perception that respondent's income was average or very low. The mean reported income of the sample was 29,228 dollars and the median income was 19,944. After finishing the survey, respondents were offered the option of purchasing between zero and five lottery tickets for one dollar each. Participants in the relative poverty condition bought on average more lottery tickets, suggesting that poverty makes people more likely to take risky financial decisions.

${ }_{6}^{5}$ In all the analyses, the standard errors are clustered by household.

${ }^{6} \mathrm{~A}$ careful analysis of the responses suggests that a few respondents completed the questionnaire too quickly or with no proper comprehension of the questions. I define answers of sufficient quality as those that meet two requirements: respondents reported that they could understand the questions, and they devoted sufficient time to completing the questionnaire. The analyses exclude 45 respondents who reported that they found the questions extremely difficult to answer, suggesting that they did not properly understand the questions. The modal response time was 98 second, and I drop the 164 responses completed in half that time, i.e. 49 seconds or less. A case-by-case analysis of these fast responses revealed numerous instances of inattentive reading (i.e. answering " 5 " to most questions or providing highly inconsistent answers). Including these responses does not alter the main conclusions, but results in somewhat larger standard errors.

${ }^{7}$ These frequencies are estimated based on the total number of valid cases. In addition, 108 people in the lowinequality condition and 96 people in the high-inequality condition reported that they did not know their household's income or that they preferred not to report it. The fact that non-response is lower in the high-income condition suggests that shame did not motivate more people in this condition to hide their income by failing to reply. ${ }^{8}$ In the low inequality condition, the correlation between net personal income and non-response is -0.24 , whereas in the high inequality condition it is -0.23 .
} 
${ }^{9}$ These analyses divide respondents into the low- and high-income group, derived from the main income question as described above. Because this question was not asked in the control group, the analyses exclude respondents in that group. Later analyses use alternative operationalizations of income and therefore include all respondents.

${ }^{10}$ This information was reported by respondents in a separate module of the survey, which was appended to the experimental module. The Longitudinal Internet Study for the Social Sciences imputes the missing data to the net income variable by using other information provided by the respondent in this and other surveys. Of the 1693 respondents who started the survey, 1363 or 81 percent, reported their personal net income. LISS imputed income for an additional 244 individuals. Due to absence of sufficient information to impute, we lack net personal income data for 86 individuals or just 5 percent of respondents. As can be expected, we observe more missing cases $(\mathrm{N}=191)$ when focusing on net household income. For this variable, we have self-reported or imputed information for 1502 respondents.

${ }^{11}$ The results remain substantively unchanged when using brutto personal income and brutto household income (available on request).

${ }^{12}$ The results are similar when using estimates from the other models. 